\title{
Wide-band metamaterial perfect absorber through double arrow shape printed on a thin dielectric
}

\author{
Siti Adlina Md Ali ${ }^{1}$, Maisarah Abu², Siti Normi Zabri ${ }^{3}$, Shipun Anuar Hamzah ${ }^{4}$ \\ ${ }_{1,2,3}$ Centre for Telecommunication Research and Innovation, Fakulti Kejuruteraan Elektronik \& Kejuruteraan Komputer, \\ Universiti Teknikal Malaysia Melaka, Malaysia \\ ${ }^{4}$ Jabatan Kejuruteraan Elektronik, Fakulti Kejuruteraan Elektrik dan Elektronik, Universiti Tun Hussein Onn Malaysia \\ 86400 Parit Raja, Johor, Malaysia
}

\begin{tabular}{|c|c|}
\hline Article Info & ABSTRACT \\
\hline Article history: & \multirow{10}{*}{$\begin{array}{l}\text { A wide-band metamaterial perfect absorber was introduced. The dual arrow } \\
\text { shapes and the ground plane were in between the } 0.0035 \lambda \text { TLY-3. Lump } \\
\text { element technique was applied to enhance the absorption bandwidth, which } \\
\text { was connected between both of the arrow structures. The limitation during } \\
\text { fabrication process in using lump element, had seriously restricted its practical } \\
\text { applications for microwave absorption. Then, a very thin line was connected } \\
\text { between both arrow structures to represent the resistance by lump element } \\
\text { which was expected to ease the fabrication process and practical applications } \\
\text { as well. Four cases were analyzed: double arrow, double arrow with lump } \\
\text { connected, double arrow with lump connected and } 9 \mathrm{~mm} \text { air gap, and thin line } \\
\text { connected with } 6 \mathrm{~mm} \text { air gap. The fourth case achieved the highest } \\
\text { operational absorbency frequency, which developed about } 7.38 \mathrm{GHz} \text { ( } 3.87 \\
\mathrm{GHz} \text { to } 11.25 \mathrm{GHz} \text { ) approximately to } 7.38 \mathrm{GHz} \text {. Three resonant frequencies } \\
\text { were achieved; } 4.17 \mathrm{GHz}, 6.09 \mathrm{GHz} \text { and } 10.30 \mathrm{GHz} \text { with perfect absorbency. } \\
\text { These properties are expected to be used in practical applications such as } \\
\text { satellite and radar communications transmission. These properties of the } \\
\text { metamaterial absorber could increase the functionality of the metamaterial } \\
\text { absorber to be used in any application especially in reducing radar cross } \\
\text { section for stealth application. }\end{array}$} \\
\hline Received Dec 10, 2020 & \\
\hline Revised Mar 30, 2021 & \\
\hline Accepted Jul 24, 2021 & \\
\hline Keywords: & \\
\hline Dielectric & \\
\hline Double arrow & \\
\hline Lump & \\
\hline Thin line & \\
\hline Wide-band & \\
\hline
\end{tabular}

This is an open access article under the CC BY-SA license.

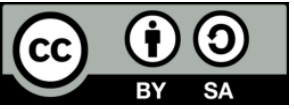

\section{Corresponding Author:}

Maisarah Abu

Centre for Telecommunication Research and Innovation

Fakulti Kejuruteraan Elektronik \& Kejuruteraan Komputer

Universiti Teknikal Malaysia Melaka, Malaysia

Email:maisarah@utem.edu.my

\section{INTRODUCTION}

Metamaterials perfect (MMP) absorber was first introduced by Landy [1]. It successfully attracts researchers' interests due to the versatility of controlling electromagnetic (EM) wave incident, intangibility nature of property features [2]. Numerous interesting properties are found concerning metamaterials; left handed [3], electromagnetic band gap (EBG) [4], frequency selective surface (FSS) [5], artificial magnetic conductor (AMC) [6] and absorber [7]. The left handed structure offers an unusual material properties which are double negative of permittivity and permeability at resonating frequency, EBG suppresses unwanted surface waves within a band gap, FSS selects specific electromagnetic waves like a filter effect and AMC reinforce an image currents with the real currents for more efficient low profile antenna.

Radar absorbing materials have been traditionally used for stealth purposes in the military domain. Recently, they have also become of great interest for solving electromagnetic interference problems in the 
aerospace domain [8]. In particular, satellites may comprise multiple antennas relatively close to one another, which can affect their performances. A way to decrease the multipath crosstalk between antennas is to cover the satellite platform with an absorbing material.

Metamaterial (MMA) absorber is used to reduce either scattering or reflection of an object. The incident waves are absorbed by the structure, cancel out the electric and magnetic field, and guide the surrounding incoming wave. The most classical structures for electromagnetic absorbers are Salisbury screen and Jaumann [1]. Losses of Salisbury absorber are developed with a resistive sheet that is placed at a distance of $\lambda / 4$ over the ground plane. Besides, the resistive sheets are stacked over each other for Jaumann absorbers. Although both absorbers are applied numerously in microwave technology, the bandwidth limits to a very narrow band, suffers from a large volume if broadband absorption is required [9], [10].

The evolution of MMP absorber has always been one of the challenging aspects in front of the scientific community. In principle, the perfect absorber is obtained by minimizing the reflection and eliminating the transmission. MMP absorbers are often built from patterned metallic layer and continuous metallic layer separated by a dielectric substrate. The patterned metallic layer which is printed on the front side is used to minimize the reflection by impedance matching, whereas the back continuous metallic layer is to block the transmission.

The exotic nature of application areas for metamaterial (MMA) have attracted many researchers. Many applications are found in practice such as filters [11], recflector [12], focus antenna beam [13] and absorbers [7], [14]. To date various MMAs are designed, such as single band [15], dual band [16], multi-band [17], wide-band [18], tunable or switching [19], and flexible MMA [20]. Researchers have also focused on wide-band MMA absorber due to the development of wide-band operation in microwave communication equipment. It can also be utilized easily in the real life and in many applications. In order to realize the wideband of MMA absorber, various methods have been suggested which are lump element [21], multi-layer structure [22], different patches size (mufti-resonance structure) [23], patterned ground structure [24], and meandered line [25]. Similar to the performance of single band MMP absorber, wide-band MMA absorber with a high absorption is also extremely preferred in terms of application perspective. The problem in searching for a method to solve the problem has led to the introduction of a thin line to represent the resistance of lump element, connected between bots of the arrow structures, which produces a wide-band MMA absorber with nearly perfect absorption along the operating band.

Past researchers have developed wide-band absorber by using various technique, subject to the main constrain of the structure. Although some applied patterned ground planes are less complicated to develop, they lack of the bandwidth increment [26], [27]. A bidirectional absorber with metal patterns on both sides of the dielectric substrate may be used, but, it is not achievable by a mere duplication of metallic patterns. A complication arises wherein a unidirectional bandwidth enhanced absorber is designed initially which is then modified to realize the bidirectional bandwidth enhanced absorber. Another bandwidth enhancement technique is by using multilayer structure [28], contributing to the largest volume of the overall thickness of the structure. The most popular technique is by using the lump element for its highest bandwidth enhancement [29], [30]. However, this technique requires a complicated developing process and is also limited in terms of its utilization in real life. The problem in finding for a method to solve the issue has led to the introduction of meandered line; a very thin line to represent the resistance in order to develop absorber.

In this paper, we investigated a wideband metamaterial perfect absorber (MPA) based on dual arrows structure. The dual arrows patch and the ground plane were in between the $0.0035 \lambda$ Taconic TLY -3 . Lump element technique was applied to enhance the absorption bandwidth, which was connected between both arrows. Then, a very thin line was connected between both arrows to represent the resistance by lump element which was easier to fabricate and apply in practical applications. Four cases were being analyzed: double arrow, double arrow with lump connected, double arrow with lump connected and $9 \mathrm{~mm}$ air gap, and thin line connected with $6 \mathrm{~mm}$ air gap.

\section{RESEARCH METHOD}

The proposed unit cell of MMP absorber was based on dual arrow structure. Dielectric substrate was placed in between the printed metallic and the ground plane. The selected dielectric substrate was Taconic TLY-3 with a dielectric constant of $\varepsilon=2.33$ and a loss tangent of $\delta=0.0012$, and its thickness was $0.25 \mathrm{~mm}$. The employed lossy metal was copper with an electric conductivity of $5.8 \times 107 \mathrm{~S} / \mathrm{m}$ and a thickness of $35 \mu \mathrm{m}$. CST (computer simulation technology) Microwave Studio software was used to perform the full-wave EM simulation. The boundary condition of unit cell was set to be periodic conditions in $\mathrm{x}-\mathrm{y}$ plane, and open boundary for $\mathrm{z}$ direction in the free space. Normally-incident EM wave was polarized, and the electric and the magnetic fields were parallel to $\mathrm{x}$ and $\mathrm{y}$ axis, respectively. The absorption was calculated by using (1). Meanwhile, the absorption of general MMP absorber was calculated by using (2), because the structure was backed by a metallic film, making the transmission nearly zero.

Wide-band metamaterial perfect absorber through double arrow shape printed on a ... (Siti Adlina Md Ali) 


$$
\begin{aligned}
& A(\omega)=1-\left|S_{11}(\omega)\right|^{2}-\left|S_{21}(\omega)\right|^{2} \\
& A(\omega)=1-\left|S_{11}(\omega)\right|^{2}
\end{aligned}
$$

where: $A(\omega)=$ absorption

\section{$S_{11}(\omega)=$ reflection coefficient}

$S_{21}(\omega)=$ transmission coefficient

Moreover, the transmission was reduced when effective permittivity $\varepsilon(\omega)$ and effective permeability $\mu(\omega)$ provided unity normalized impedance, $\mathrm{z}=\sqrt{ } \mu(\omega) / \varepsilon(\omega)$. Hence, at these frequency points, normalized impedance which was perfectly matched with the free space impedance results in $R(\omega)$ to be minimized. Thus, maximizing the absorption of the proposed absorber. The normalized input impedance is calculated using (3)

$$
z= \pm \sqrt{\frac{\left(1+S_{11}\right)^{2}-\left(S_{21}\right)^{2}}{\left(1-S_{11}\right)^{2}-\left(S_{21}\right)^{2}}}
$$

Since, the proposed absorber is completely backed with a metallic ground plane, therefore, (4) can be written in the form of only reflection coefficient (S11) as given by (4)

$$
z= \pm \frac{1+S_{11}}{1-S_{11}}
$$

CST software was used to design a double arrow MMP absorber. Initially, a triangular polygon was built under curve tools. Then the triangular polygon was given a $0.035 \mathrm{~mm}$ thickness by using PEC material trough extrude tools. The triangular patches were then added up with small rectangular patch $(3 \mathrm{~mm} \times 2 \mathrm{~mm})$ to develop an arrow shape. The arrow patch at the up-left corner of the substrate was rotated at $90 \mathrm{o}$ angle so that there was another arrow patch defined at the bottom-right corner. Initially, a double arrow patch which was printed on TLY-3 dielectric was simulated, being claimed as case 1 . Then, the reflection coefficients of the MMP absorber were carried out as the double arrow were connected with the lump element (case 2) and as there was a gap between the dielectric and ground plane (case 3). Due to the complexity during the fabrication and limitation on application later, the lump element was being replaced by a very thin line to represent the losses for developing MMP absorber (case 4).

Figure 1 proposes unit cell of MMP absorber where Figure 1 (a) shows a configuration layer and Figure 1 (b) shows the top view of the double arrow. Table 1 shows the optimized parameter for the unit cell of a double arrow MMP absorber. Meanwhile, Table 2 shows the four cases being investigated for the double arrow MMP absorber.

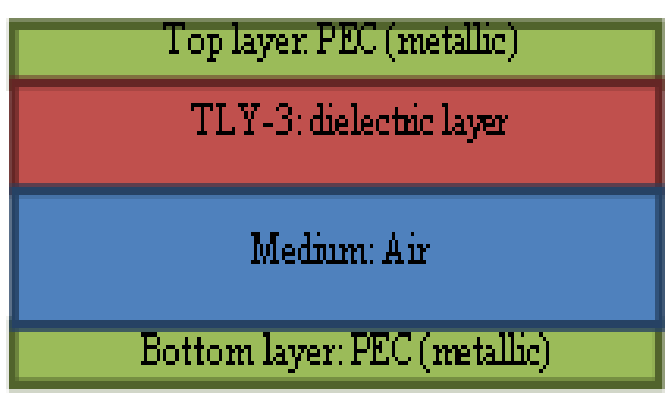

(a)

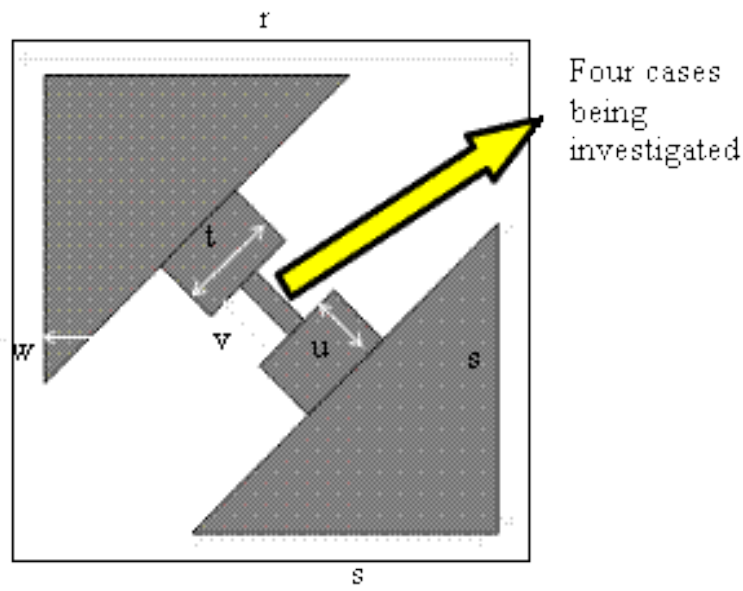

(b)

Figure 1. Multiband MMP absorber; (a) configuration layer (side view), (b) design of the double arrow (top view) 
Table 1. The optimized dimensions for the unit cell of double arrow MMP absorber

\begin{tabular}{lcc}
\hline \multicolumn{1}{c}{ Description } & Variable & Dimension $(\mathrm{mm})$ \\
\hline Substrate width & $r$ & 15 \\
Arrow length & $s$ & 8.76 \\
Rectangular length & $t$ & 3 \\
Rectangular width & $u$ & 2 \\
Gap between arrows & $v$ & 2 \\
Gap & $w$ & 1 \\
\hline
\end{tabular}

Table 2. Four cases that being analyzed for the unit cell of double arrow MMP absorber

\begin{tabular}{cl}
\hline Cases & \multicolumn{1}{c}{ Description } \\
\hline Case 1 & without line or lump \\
Case 2 & lump connected \\
Case 3 & lump connected with 9 mm air gap \\
Case 4 & thin line connected with 6 mm air gap \\
\hline
\end{tabular}

\section{RESULTS AND DISCUSSION}

Figure 2 is the absorption spectra for the four cases as illustrated in Table 2. Initially, the reflection coefficient of double arrow without line or lump connected was plotted. Two resonance frequencies were reported: $10.72 \mathrm{GHz}$ and $14.56 \mathrm{GHz}$ with reflection of $-27.23 \mathrm{~dB}$ and $-25.32 \mathrm{~dB}$ respectively. For case $2,1 \Omega$ of lump element was connected between both arrows which developed $-24.07 \mathrm{~dB}$ and $-22.07 \mathrm{~dB}$ of reflections at $11.07 \mathrm{GHz}$ and $14.97 \mathrm{GHz}$ respectively. Both cases were limited in producing bandwidth where less than $1 \%$, consequently restricted the application of the structure. The MMP structure was then being upgraded by adding the $9 \mathrm{~mm}$ air gap, known as case 3 to broaden the operational frequency of the structure. The findings yielded that this method successfully enhanced the bandwidth to $4.77 \mathrm{GHz}$ starting at $3.05 \mathrm{GHz}$ to $7.82 \mathrm{GHz}$. It also produced two resonance frequencies; $3.29 \mathrm{GHz}$ and $5.98 \mathrm{GHz}$ with almost perfect absorbance. Table 3 shows the summary of three cases in terms of operation frequency, bandwidth and absorbency.

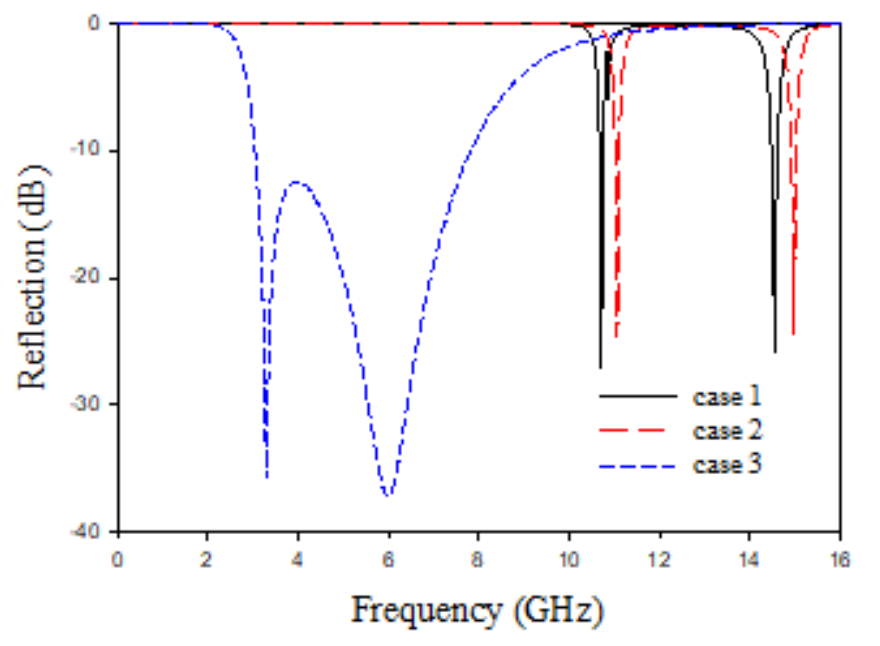

Figure 2. Simulated reflection of unit cell double arrow MMP absorber for three cases

Table 3. The summary of unit cell double arrow MMP absorber

\begin{tabular}{cccc}
\hline Case & Operating frequency $(\mathrm{GHz}-\mathrm{GHz})$ & Bandwitdh $(\mathrm{GHz})$ & Absorbency $(\%)$ \\
\hline Case 1 & $10.68-10.76$ & 0.75 & $99.99_{10.72 \mathrm{GHz}}, 99.99_{14.56}$ \\
& $14.48-14.62$ & 0.96 & $\mathrm{GHz}$ \\
Case 2 & $11.02-11.11$ & 0.81 & $99.99_{11.07 \mathrm{GHz}}, 99.99_{14.97}$ \\
& $14.92-15.04$ & 0.80 & $\mathrm{GHz}$ \\
Case 3 & $3.05-7.82$ & 4.77 & $99.99_{3.29} \mathrm{GHz}, 99.99_{5.98 \mathrm{GHz}}$ \\
\hline
\end{tabular}

Even though the third case developed a wide-band bandwidth of more than $100 \%$ of enhancement, the use of lump element itself was a major limitation as applied in real life. Moreover, it also involved the complexity in developing process as a detail precaution must be taken into account during soldering the lump element in a large size of an array for MMP absorber. The problem in searching for a method to solve the issue led to the introduction of a very thin line to represent the resistance by the lump element, gearing toward more practical and easier method to utilize in real application. In case three, the thin line 
$(0.6 \mathrm{~mm} \times 2 \mathrm{~mm})$ connected both arrows and the $9 \mathrm{~mm}$ air gap in between the dielectric and ground plane was reduced to $6 \mathrm{~mm}$.

Figure 3 shows the reflection and absorption of both case 3 and 4. The lump element in case 3 was being replaced by a very thin line. Bandwidth showed increment of $2.61 \mathrm{GHz}$ from $4.77 \mathrm{GHz}$ to $7.38 \mathrm{GHz}$ from case 3 to case 4 . The operating frequency for case 4 started from $3.87 \mathrm{GHz}$ to $11.25 \mathrm{GHz}$ covering $\mathrm{S}$ band, C-band and L-band frequencies which is the major advantage to widen the use of MMP absorber in real life applications. Three resonance peaks occurred; $4.17 \mathrm{GHz}, 6.09 \mathrm{GHz}$ and $10.30 \mathrm{GHz}$ with a very good absorbency $99.99 \% \approx 100 \%$. Table 4 shows the summary of bandwidth, resonance frequency and absorbency for both case 3 and case 4 .

Table 4. The summary ofe unit cell double arrow MMP absorber

\begin{tabular}{cccc}
\hline Case & Bandwitdh $(\%)$ & Resonance frequency $(\mathrm{GHz})$ & Absorbency $(\%)$ \\
\hline Case 3 & 4.77 & $3.29,5.98$ & $99.99,99.99$ \\
Case 4 & 7.38 & $4.17,6.09,10.30$ & $99.99,99.99,99.99$ \\
\hline
\end{tabular}

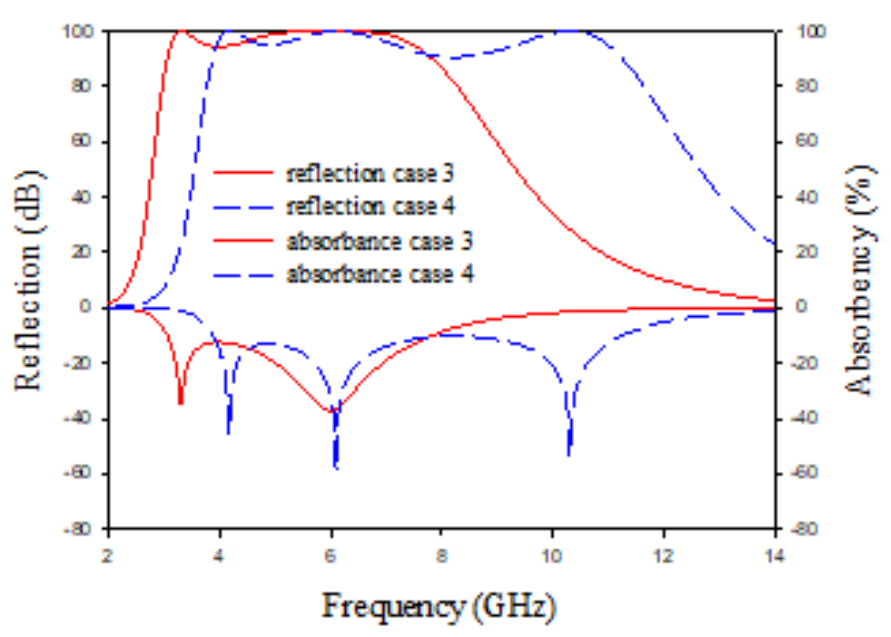

Figure 3. Simulated reflection of unit cell double arrow MMP absorber for two cases

Figure 4 (a) shows the real and imaginary parts of the simulated input impedance for case 4 . The impedance matching of the imaginary and real parts were approximately unity and zero, respectively. Thus, there was no reflection wave in the MMP absorber. Moreover, the normalized input impedance further revealed that the proposed structure surface input impedance and free space impedance were well matched to the values of $377 \Omega$ and $0 \Omega$. The distribution of the surface current on both top and the bottom metallic layer at each resonant frequency was observed to understand the mechanism of MMP absorber. Meanwhile, Figure 4 (b) shows the distribution of the anti-parallel surface currents on the front and back metallic layers for each peak. Clearly, anti-parallel direction (going up and down alternately) of the currents was observed across the entire working bandwidth, indicating the occurrence of magnetic resonances. The E-Field distribution concentrated on the vertical axis whereas the H-field distribution intensified on the horizontal axis ( $\mathrm{Y}$-axis for E-field and $\mathrm{X}$-axis for $\mathrm{H}$-field). Hence, circulating current loops were generated within the structure at resonant frequencies, creating magnetic excitation within the structure. The electric and magnetic excitation overlapped to create electromagnetic absorption.

The proposed wide-band double arrow MMP absorber was compared with some previous absorbers in terms of overall thickness, substrate, bandwidth and method applied as shown in Table 5. The comparisons were based on the lowest working wavelength, $\lambda_{\mathrm{fL}}$. Various methods were suggested namely lump element, multi-layer structure, different patches size, patterned ground structure, and meandered line. However, each of the methods led to sentence limitation; complicated design process for both lump element and patterned ground, largest volume for multi-layer structure and different patches size. The proposed MMP absorber shows the highest bandwidth increment, $176.98 \%$ as compared to other absorbers. A very thin line replaces the lump resistance to create the loss of the absorber, easing the developing process and giving more practical application to utilize in real applications. The overall thickness of the proposed project is considered compact compared to [24] and [30], and thicker compared to others. 


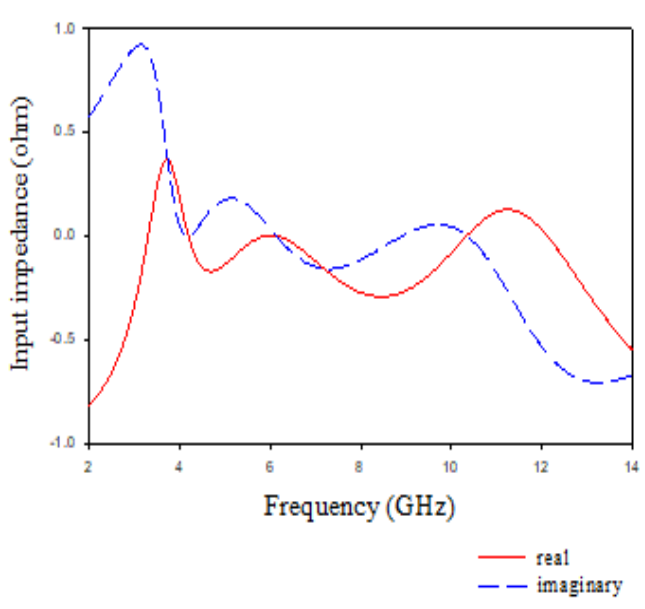

(a)

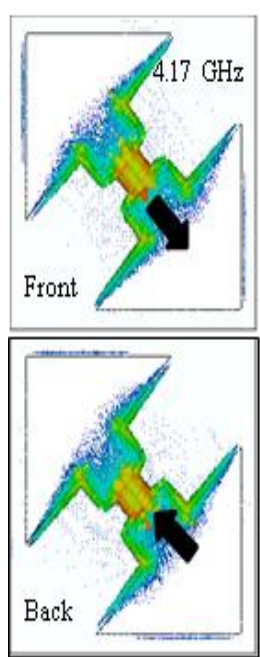

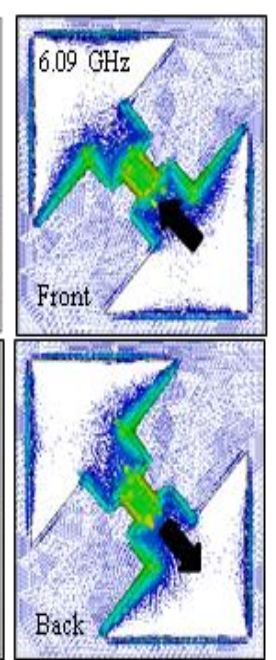

(b)

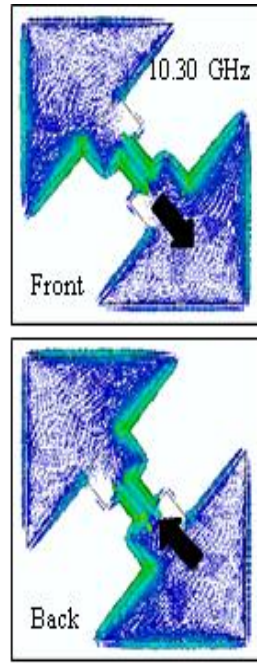

Figure 4. Simulated results of unit cell double arrow MMP absorber; (a) input impedance, (b) surface current distribution

Table 5. Review on wide-band absorber

\begin{tabular}{cccl}
\hline References year & Overall thickness & Bandwidth $(\%)$ & \multicolumn{1}{c}{ Method } \\
\hline$[3], 2018$ & $0.0110 \lambda_{6.5 \mathrm{GHz}}$ & 56.92 & Patterned ground plane \\
{$[18], 2019$} & $0.0593 \lambda_{7.1 \mathrm{GHz}}$ & 102.82 & Multi-layer structure \\
{$[19], 2019$} & $0.0699 \lambda_{13.38 \mathrm{GHz}}$ & 11.97 & Patterned ground plane \\
[23], 2019 & $0.0679 \lambda_{12.2 \mathrm{GHz}}$ & 54.45 & Meandered wire \\
{$[24], 2019$} & $0.0914 \lambda_{11.8 \mathrm{GHz}}$ & 71.39 & Different patches size \\
[28], 2020 & $0.1242 \lambda_{13.58 \mathrm{GHz}}$ & 25.55 & Lump element \\
[29], 2020 & $0.0724 \lambda_{10.06 \mathrm{GHz}}$ & 115.74 & Meandered wire \\
[30], 2020 & $0.0997 \lambda_{9.1 \mathrm{GHz}}$ & 52.75 & Lump element \\
Proposed project & $0.0878 \lambda_{4.17 \mathrm{GHz}}$ & 176.98 & Thin line to represent lump resistance \\
\hline
\end{tabular}

\section{CONCLUSION}

The wide-band metamaterial perfect absorber (MPA) is successfully designed in this paper. The dual arrow shapes and the ground plane are in between the $0.0035 \lambda$ Taconic TLY-3. Lump element technique is applied to enhance the absorption bandwidth, which is connected between double arrow structures. The limitation during fabrication process in using lump element, had seriously restricted its practical applications for microwave absorption. Then, a very thin line is connected between both arrow structures to represent the resistance by lump element which is easier to fabricate and apply in practical applications. Four cases are being analyzed: double arrow, double arrow with lump connected, double arrow with lump connected and 9 $\mathrm{mm}$ air gap, and thin line connected with $6 \mathrm{~mm}$ air gap. The fourth case achieves the highest operational absorbency frequency, about $7.38 \mathrm{GHZ}(3.87 \mathrm{GHz}$ to $11.25 \mathrm{GHz})$ approximately to $7.38 \mathrm{GHz}$. Three resonant frequencies are achieved; $4.17 \mathrm{GHz}, 6.09 \mathrm{GHz}$ and $10.30 \mathrm{GHz}$ with absorbency $99.99 \% \approx 100 \%$ (perfect absorbency). These properties are expected to be used in practical applications such as satellite and radar communication transmission. These properties of the metamaterial absorber can increase the functionality of the metamaterial absorber to be used in any application especially in reducing radar cross section for stealth application.

\section{ACKNOWLEDGEMENTS}

The support of Universiti Teknikal Malaysia Melaka (UTeM) is greatly acknowledged. The research has been funded by UTeM Zamalah Scheme.

\section{REFERENCES}

[1] N. I. Landy, S. Sajuyigbe, J. J. Mock, D. R. Smith, and W. J. Padilla, "Perfect Metamaterial Absorber," Physical Review Letters, vol. 100, no. 207402, 2008. 
[2] R. W. Ziolkowski, and N. Engheta, "Metamaterial: Physics and Engineering Explorations," John Wiley \& Sons Ltd, 2006.

[3] H. Singh, N. Mittal, and O. Arora, "Designing and Analysis of Frequency Reconfigurable Double Negative Flower Leaf Metamaterial Absorber," Materials Today: Proceedings, 2020, doi: 10.1016/j.matpr.2020.04.122.

[4] M. Abu, S. A. M. Ali, H. Hassan, and I. M. Ibrahim, "Characterization of Artificial Magnetic Conductor, Electromagnetic Band Gap and Frequency Selective Surface," Journal of Telecommunication, Electronic and Computer Engineering JTEC, vol. 10, no. 2-6, pp. 139-143, 2019.

[5] S. A. M. Ali, M. Abu, and S. N. Zabri, "Improvements of Trapezoid Antenna Gain Using Artificial Magnetic Conductor and Frequency Selective Surface," Indonesian Journal of Electrical Engineering and Computer Science (IJEECS), vol. 20, no. 1, pp. 281-286, 2020, doi: 10.11591/ijeecs.v20.i1.pp281-286.

[6] M. Abu, S. A. Md. Ali, and H. Asha'ri, "Compact Microstrip Monopole Antenna with Enhanced Gain Using Artificial Magnetic Conductor AMC," Journal of Physics: Conference Series, Optics Express, vol. 21, no. 26, pp. 32484-32490, 2020, doi: 10.1088/1742-6596/1502/1/012001.

[7] M. Abu, H. Hassan, M. S. I. M. Zin, S. A. M. Ali, and M. Muhammad, "An Analysis of Dual-Band Octagonal Ring Metamaterial Absorber," International Conference on Computer and Communication Engineering ICCCE, 2016, pp. 25-29, doi: 10.1109/ICCCE.2016.19.

[8] O. Rance, A. C. Lepage, X. Begaud, K. Elis, and N. Capet, "Oblique Wide-Angle Multi-Sector Metamaterial Absorber for Space Applications," Applied Sciences, vol. 9, no. 3425, pp. 1-13, 2019, doi: 10.3390/app9163425.

[9] M. Shan, T. Chen, J. Lei, L. Yang, and X. Tan, "Triple-band Polarization-Independent Ultrathin Metamaterial Absorber," Progress in Electromagnteics Reseacrh M, vol. 77, pp. 93-102, 2019, doi: 10.2528/PIERM18110602.

[10] J. Wu, F. Zhang, Q. Li, J. Chen, Q. Feng, and L. Wu, "Infrared Five Band Polarization Insensitive Absorber with High Absorptivity Based on Single Complex Resonator," Optics Communications, vol. 456, no. 124575, pp. 1-5, 2020, doi: 10.1016/j.optcom.2019.124575.

[11] M. D. Gregory et al., "A Low Cost and Highly Efficient Metamaterial Reflector Antenna," IEEE Transactions on Antennas and Propagation, vol. 66, no. 3, pp. 1545-1548, March 2018, doi: 10.1109/TAP.2017.2781151.

[12] M. M. Gajibo, M. K. A. Rahim, N. A. Murad, O. Ayop, and H. A. Majid, "Switchable Wideband Metamaterial Absorber and AMC Reflector for X-band Applications and Operations," TELKOMNIKA Telecommunication Computing Electronics and Control, vol. 16, no. 4, pp. 1535-1541, 2018, doi: 10.12928/TELKOMNIKA.v16i4.9065.

[13] M. U. Afzal, K. P. Essellem, and A. Lalbakhsh, "A Metasurface to Focus Antenna Beam at Offset Angle," 2nd URSI Atlantic Radio Science Meeting AT-RASC, 2018, pp. 1-4, doi: 10.23919/URSI-AT-RASC.2018.8471483.

[14] S. A. MD. Ali, M. Abu, and S. N. Zabri, "A Review: The Development of Metamaterial Absorber," International Journal of Integrated Engineering, vol. 12, no. 1, pp. 72-80, 2020.

[15] M. M. Gajibo, M. K. A. Rahim, N. A. Murad, O. Ayop, B. D. Bala, and H. A. Majid, "X Band Operations Metamaterial Absorber with Extended Circular Ring Topology for Size Reduction,” Indonesian Journal of Electrical Engineering and Computer Science, vol. 6, no. 1, pp. 180-184, 2017, doi: 10.11591/ijeecs.v6.i1.pp180184.

[16] J. Song, L. Wang, Mi. Li, and J. Dong, "A Dual-Band Metamaterial Absorber with Adjacent Absorption Peaks," Journal of Physics D: Applied Physics, vol. 51, no. 38, pp. 385105, 2018.

[17] A. Hoque, M. T. Islam, A. F. Almutairi, T. Alam, M. J. Singh, and N. Amin, "A Polarization Independent QuasiTEM Metamaterial Absorber for X and Ku Band Sensing Applications," Sensors, vol. 18, no. 12, pp. 1-16, 2018, doi: $10.3390 / \mathrm{s} 18124209$.

[18] T. Q. H. Nguyen, T. K. T. Nguyen, T. N. Cao, H. Nguyen, and L. G. Bach, "Numrical Study of a Broadband Metamaterial Absorber using a Single Split Circle Ring and Lumped Resistors for X Band Applications," AIP Advances, vol. 10, no. 8, pp. 1-9, 2020, doi: 10.1063/1.5143915.

[19] M. G. Mustapha, et al., "Polarization Insensitive Switchable Metamaterial Absorber/Reflcetor for X Band Applications," Bulletin of Electrical Engineering and Informatics (BEEI), vol. 9, no. 6, pp. 2443-2448, 2020, doi: 10.11591/eei.v9i6.2196.

[20] Y. J. Kim, et al., "Flexible Ultrathin Metamaterial Absorber for Wide Frequency Band, Based on Conductive Fibers," Science and Technology of Advance Materials, vol. 19, no. 1, pp. 711-717, 2018, doi: 10.1080/14686996.2018.1527170.

[21] Y. Kim, H. J. Sub, Y. J. Yoo, and B. X. Khuyen, "Ultrathin Microwave Metamaterial Absorber Utilizing Embedded Resistors," Jounal of Physics D: Applied Physics, vol. 50, no. 40, pp. 1-11, 2015, doi: 10.1088/1361-6463/aa82f4.

[22] K. Chen, X. Luo, G. Ding, J. Zhao, Y. Feng, and T. Jiang, "Broadband, Microwave Metamaterial Absorber with Lumped Resistor Loading,” EPJ Applied Metamaterials, vol. 6, no. 1, pp. 1-7, 2019, doi: 10.1051/epjam/2018011.

[23] Z. Zhang, L. Zhang, X. Chen, Z. Wu, Y. He, Y. Lv, and Y. Zou, "Broadband Metamaterial Absorber for LowFrequency Microwave Absorption in the S-Band and C-Band," Journal of Magentism and Magnetic Materials, vol. 425, p. 166075, 2019, doi: 10.1016/j.jmmm.2019.166075.

[24] H. S. Singh, "Super Compact Ultrathin Quad-Band with Wide Angle Stability Polarization Independent Metamaterial Absorber," Microwave Optical Technology Letters, vol. 62, no. 2, pp. 718-725, 2019, doi: $10.1002 / \mathrm{mop} .32054$.

[25] D. H. Tiep, B. X. Khuyen, B. S. Tung, Y. Kim, K. J. Sub, V. D. Lam, and Y. Lee, "Enhanced-Bandwitdh Perfect Absorption Based on Hybrid Metamaterial," Optical Materials Express, vol. 8, no. 9, pp. 2751-2759, 2018, doi: 10.1364/OME.8.002751. 
[26] L. Stephen, N. Yogesh, and V. Subramanian, "Realization oF Bidircetional, Bandwith-Enhanced Metamaterial Absorber for Microwave Applications," Scientific Reports, pp. 1-9, 2019, doi: 10.1038/s41598-019-46464-6.

[27] J. B. O. de Araújo, G. L. Siqueira, E. Kemptner, M. Weber, C. Junqueira, and M. M. Mosso, "An Ultrathin and Ultrawideband Metamaterial Absorber and an Equivalent-Circuit Parameter Retrieval Method," IEEE Transactions on Antennas and Propagation, vol. 68, no. 5, pp. 3739-3746, May 2020, doi: 10.1109/TAP.2020.2963900.

[28] Q. Wang, and Y. Cheng, "Compact and Low Frequency Broadband Microwave Metamaterial Absorber Based on Meander wire Structure Loaded Resistors," AEU-International Electronic Communication, vol. 120, pp. 1-8, 2020, doi: 10.1016/j.aeue.2020.153198.

[29] K. S. L. Al-Badri, "Electromagnetic Broad Band Absorber Based on Metamaterial and Lumped Resistance," Jounal of King Arab Saudi University-Science, vol. 32, no. 1, pp. 501-506, 2020, doi: 10.1016/j.jksus.2018.07.013.

[30] T. Q. H. Nguyen, T. K. T. Nguyen, T. N. Cao, H. Nguyen, and L. G. Bach, "Numrical Study of a Broadband Metamaterial Absorber using a Single Split Circle Ring and Lumped Resistors for X Band Applications," AIP Advances, vol. 10, pp. 1-9, 2020, doi: 10.1063/1.5143915.

\section{BIOGRAPHIES OF AUTHORS}
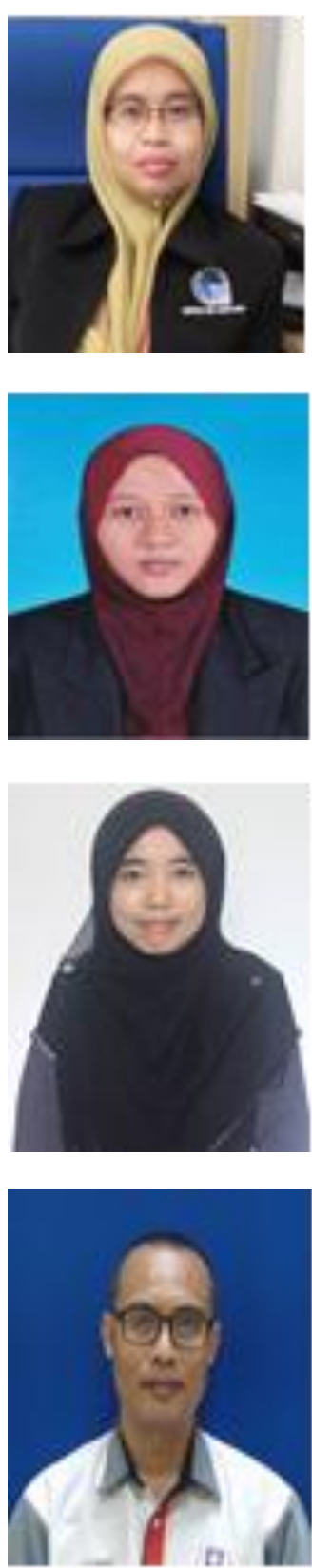

Maisarah Abu received her Bachelor Degree of Engineering in Electrical Engineering from Universiti Teknologi MARA in 2001. Then, she received her Master from Universiti Kebangsaan Malaysia in 2003. In 2012, she received her PhD from Universiti Teknologi Malaysia for her thesis on Dipole Antenna and Artifizial Magnetic Conductor for RFID Application. She was employed as a lecturer at Universiti Teknikal Malaysia Melaka since 2003. Now she is a Senior Lecturer with research interest of RF, Microwave and Antenna with Metamaterial (EBG, AMB, and FSS) and RFID.

Siti Adlina Md Ali has received her Bachelor Degree in Electronic Engineering (Telecommunication) with honours in 2009 and Master of Science in Electronic Engineering in 2017 from Universiti Teknikal Malaysia Melaka. Now she is doing her Philosophy Degree $(\mathrm{PhD})$ at Universiti Teknikal Malaysia Melaka, analyzing losses introduced by microwave absorber starting from 2018.

Siti Normi Zabri received her Bachelor Degree of Engineering in Electrical Engineering from Universiti Teknologi MARA in 2007. Then, she received her Master from The University of Sheffield in 2008. In 2015, she received her PhD from Queen's University of Belfast for her thesis on Study of Thin Resistively Loaded FSS based Microwave Absorbers. She was employed as a lecturer at Universiti Teknikal Malaysia Melaka with research interest of Frequency Selective Surface and Microwave Absorber.

Shipun Anuar Hamzah received his Bachelor Degree of Engineering in Electrical Engineering from Universiti Teknologi Malaysia in 1998. Then, he received her Master in ommunication and Computer from the same university, Universiti Teknologi Malaysia in 2000. In 2014, he received her $\mathrm{PhD}$ also from the same university, Universiti Teknologi Malaysia. He was employed as a lecturer at Universiti Tun Hussein Onn Malaysia with research interest of Active Antenna, Harmonic Suppression Antenna and Feeding circuit for balanced antenna. 